\title{
Characteristics of Carbon Dioxide Emissions from a Seismically Active Fault
}

\author{
Duoxing Yang ${ }^{1^{*}}$, Qi $\mathrm{Li}^{2}$, Lianzhong Zhang ${ }^{3}$ \\ ${ }^{1}$ Institute of Crustal Dynamics, China Earthquake Administration, Beijing 100085, China \\ ${ }^{2}$ Institute of Rock and Soil Mechanics, Chinese Academy of Sciences, Wuhan 430071, China \\ ${ }^{3}$ School of Physics, Nankai University, Tianjing 300384, China
}

\begin{abstract}
Seismically active faults are key features of the earth, and earthquake-induced carbon dioxide released from natural faults has been detected. But the link between active fault deformation and amounts of carbon dioxide emission remains poorly understood. In this paper we monitor progressive carbon dioxide levels and strain signals from the boreholes in a seismically active fault, and show that the carbon dioxide variations are sensitive to the fault deformation over the same time scale of the observations. Therefore, we preliminarily propose a mass-wave propagation model (e.g., interaction of shock waves with advection-diffusion of mass, namely the gas hammer effect) to physically interpret carbon dioxide variations due to dilation or compaction of fluid paths in the natural fault. Of particular interest is that the penetration of shock waves into the natural fault mechanically influences carbon dioxide migration.
\end{abstract}

Keywords: Natural fault; Carbon dioxide emission; Shockwaves; Carbon dioxide capture and geological storage.

\section{INTRODUCTION}

Carbon dioxide emissions have globally received more and more attention, with scientific concerns including greenhouse effects (Huang and Tan, 2014; Jean et al., 2015), health of ecosystems (Wright et al., 2018), radiative forcing (Bari and Bergot, 2018; Bansal, et al., 2019), global carbon cycle (Chatterjee et al., 2019), as well as carbon dioxide capture and geological storage (Soong et al., 2014; Yang et al., 2014; Phelps et al., 2015; Jen et al., 2017; Wang et al., 2018). The global carbon dioxide level is generally balanced by geochemical processes over a long period of time (Ballantyne et al., 2012). Studies have recognized volcanic eruption as a natural source for initial atmospheric carbon dioxide in the young earth era (Hunt et al., 2017). Annual 130 to 230 megatons of carbon dioxide have been attributed to modern volcanic activities. The global annual mean carbon dioxide level has been estimated from $280 \mathrm{ppm}$ during the 10,000 years up to the mid-18th century to $410 \mathrm{ppm}$ as of mid-2018 (Dlugokencky, 2016). Anthropogenic carbon emissions remain a leading contribution to the atmospheric carbon dioxide (Keeling et al., 2011; Soong et al., 2014). The growing imbalance between sources and sinks of the global carbon dioxide cycle has become a widespread

\footnotetext{
* Corresponding author.

Tel: 80-10-62846718; Fax: 80-10-62846718

E-mail address: yangdx@mail.iggcas.ac.cn
}

concern in the recent years (Yu et al., 2012; Mohr et al., 2014; Lin et al., 2018). Missions of industrial carbon dioxide reduction have been globally aroused (Werner et al., 2018). Currently, the volcanic outgassing has been categorized as a main natural source of the atmospheric carbon dioxide (Irwin et al., 1980). Lots of works have demonstrated that carbon dioxide emissions are accompanied by burst of tectonic earthquakes (Sorey et al., 1998), and the earth degassing of carbon dioxide spatially correlates with tectonic zones (Barnos et al., 1978; Tamburello et al., 2018). The tectonic control on the earth degassing has been extensively observed in volcanic areas at regional and local scales (Mazot et al., 2011), but its role at a continental fault scale is still poorly studied. Fault zones and relevant fracturing play a fundamental role in carbon dioxide migration by creating fluid conduits extending from the deep crust to the earth surface (Hunt et al., 2017). Of particular interest is that what happens to the global carbon dioxide level if seismically active fault-driven carbon dioxide emissions are considered. However, the knowledge of how much carbon dioxide is produced by a seismically active fault remains a big space to be better understood. The contribution of natural faults to the atmospheric carbon dioxide level should be further estimated by reproducibly accurate measurements (Ali et al., 2017; Li and Biswas, 2017; Yang et al., 2017; Ishikawa and Sekiguchi, 2018).

In this study, we have carried out continuous measuring of carbon dioxide flux produced by a seismically active fault, located at the southwestern boundary of Helan Mountains in Inner Mongolia (as shown in Fig. 1). Variations of the 

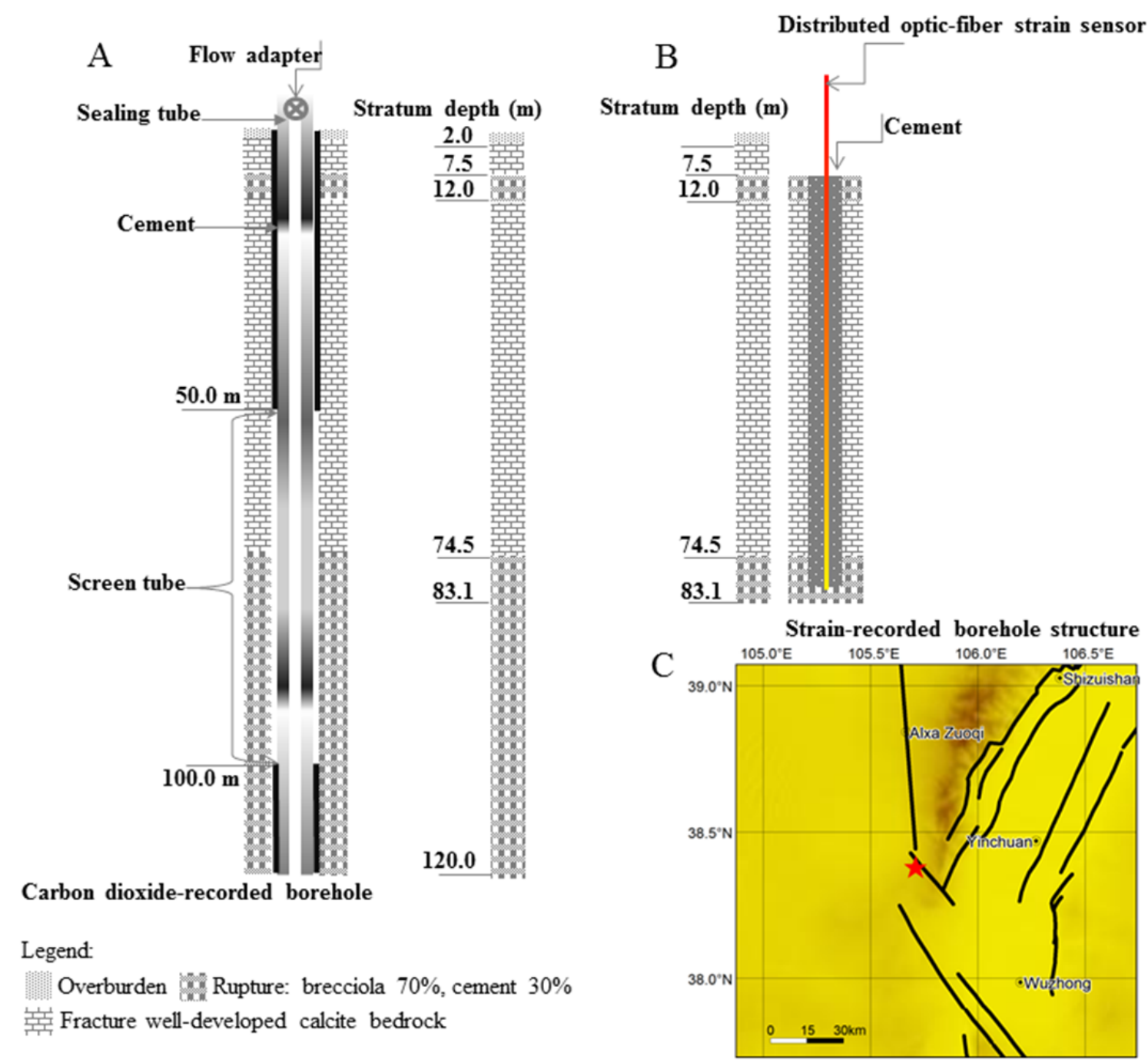

Fig. 1. Topographic map (C) of the Bayan Hot fault located at the southwestern boundary of Helan Mountains in Inner Mongolia. The black thick line near the red star represents a seismically active reverse-fault. A red star shows the underground borehole location (longitude 105.71, latitude 38.38). Upper inset: showing borehole structure ((A) carbon dioxide observed borehole and (B) strain-recorded borehole). Lower inset: legend showing stratigraphy of overburden, fracture well-developed calcite bedrocks and shear zones (e.g., rupture induced by historic earthquakes).

natural fault-driven carbon dioxide level during 2018 have been investigated. We have found seasonal fluctuations of the carbon dioxide level on a long-term increasing and then decreasing background, which synchronizes the in situ atmospheric temperature variations. Strain measurements, based on the Brillouin optical time-domain analysis (BOTDA), have shown that both fracture well-developed calcite bedrocks and earthquake-induced ruptures (e.g., shear zone) experience dilation caused by plastic deformation, followed by a rise of carbon dioxide levels. The mechanism may be contributed to either fault valve-driven fluid flow (Frank et al., 2015) or water-hammer effect (Yin, 2018), which is associated with the pressure-wave propagation (Yang et al., 2018). Furthermore, we preliminarily propose a mass-wave propagation model (e.g., interaction of shock waves with advection-diffusion of mass, namely the gas hammer effect) to physically explain carbon dioxide variations due to dilation or compaction of the natural fault.

\section{METHODS}

\section{Carbon Dioxide Data Acquisition Method}

An underground-based borehole measurement has begun more recently. The carbon dioxide monitoring borehole of the depth 120 meters is vertically drilled in the Bayan Hot fault, located at the southwestern boundary of Helan Mountains in Inner Mongolia, with each hosting dip-parallel fluid conduits (e.g., fracture well-developed calcite bedrock and earthquake-induced rupture) intersected by the borehole, and stretches along-strike of 10 meters away from the strainobserved borehole (as depicted in Fig. 1). The boreholepenetrated stratum up-down crosses the overburden, fracture well-developed calcite bedrocks and earthquake ruptures (e.g., shear zone). Two ruptures induced by historical earthquakes are solidified with rupture rocks, which are mainly composed of brecciola accounting of $70 \%$ and cement accounting of $30 \%$. An entire depth of the borehole 
is coated by two kinds of acid-resistant steel tubes. From the ground-surface to the depth of 50 meters, the sealing tube is used, and the neutral cement (no spontaneous deformation) is filled within the gap between the external circumferential surface of the tube and the borehole circumferential rock surface, isolating horizontal exchange of shallow soil gas with deep-origin carbon dioxide, and eliminating gas contamination due to shallow soil gas intrusion. Between underground depth of 50 meters and 100 meters, a screentube is used to facilitate flow freely into the borehole, without cement filled within such kind of gap as above-mentioned. Below underground depth of 100 meters downward 120 meters, the sealing tube is used, with cement filled within such kind of gap as above-described. Given that sealing condition, deep-seated carbon dioxide can converge and flow upward into the end-inlet of the sealing-tube. A single opening exhaust valve (e.g., flow adapter) is installed at the up-inlet of the tube, isolating atmospheric gas intrusion into the borehole. A Red-Infrared data acquisition instrument with the sensor embodied is physically connected with the flow adapter, recording progressive signals of carbon dioxide levels released from the borehole, beginning in the end of November, 2017. That instrument simultaneously measures both atmospheric temperature and carbon dioxide. The data acquisition period is one minute. Data from the in situ monitoring exhibits characteristics of good-quality borehole gas level data. It is notable that at the beginning of data acquisition, carbon dioxide in the borehole remains a mixture of atmospheric and deep-seated gases, meaning gas samples are contaminated. Therefore, the data measured prior to the end of November have been removed for further analysis. Eventually, we have analysed measurements of data from 1 January to 31 December during 2018. The data are re-sampled to obtain one mean value every 60 minutes.

\section{Borehole Strain Monitoring Method}

To measure the fault deformation, a distributed opticfiber strain sensor has been installed into the borehole (located at the longitude $105.71^{\circ}$ and latitude $38.38^{\circ}$ ), which is drilled in the fault in November 2017, crossing the overburden, fracture well-developed calcite bedrocks and earthquake-induced ruptures (e.g., shear zone) mainly composed of $70 \%$ brecciola and $30 \%$ cement. The stratum and borehole structure is shown in Fig. 1. The Brillouin optical time-domain analysis (BOTDA) is applied for the strain monitoring. The distributed optic-fiber strain sensor is sealed by the neutral cement (e.g., no spontaneous deformation) into the observation borehole, recording continuous strain signals every 60 minutes, with the acquisition accuracy of two million-strain (e.g., $2 \mu \varepsilon$ ). The data acquisition space-resolution is 0.05 meter along the longitudinal direction of 83.1 meter deep borehole, across which there has been significant displacement as a result of rock mass movement. After six months of the site recovers from the borehole-drilling disturbance since November 2017, the data acquisition of borehole strains has finally been carried out. Here, the strain data-acquisition period ranges from May 29 to June 2, 2018, during which period both strain signals and carbon dioxide levels are recorded simultaneously.

\section{RESULTS AND DISCUSSION}

\section{Characteristics of Carbon Dioxide Variations}

Seasonal variations of the carbon dioxide level and the atmospheric temperature are shown in Fig. 2. The carbon

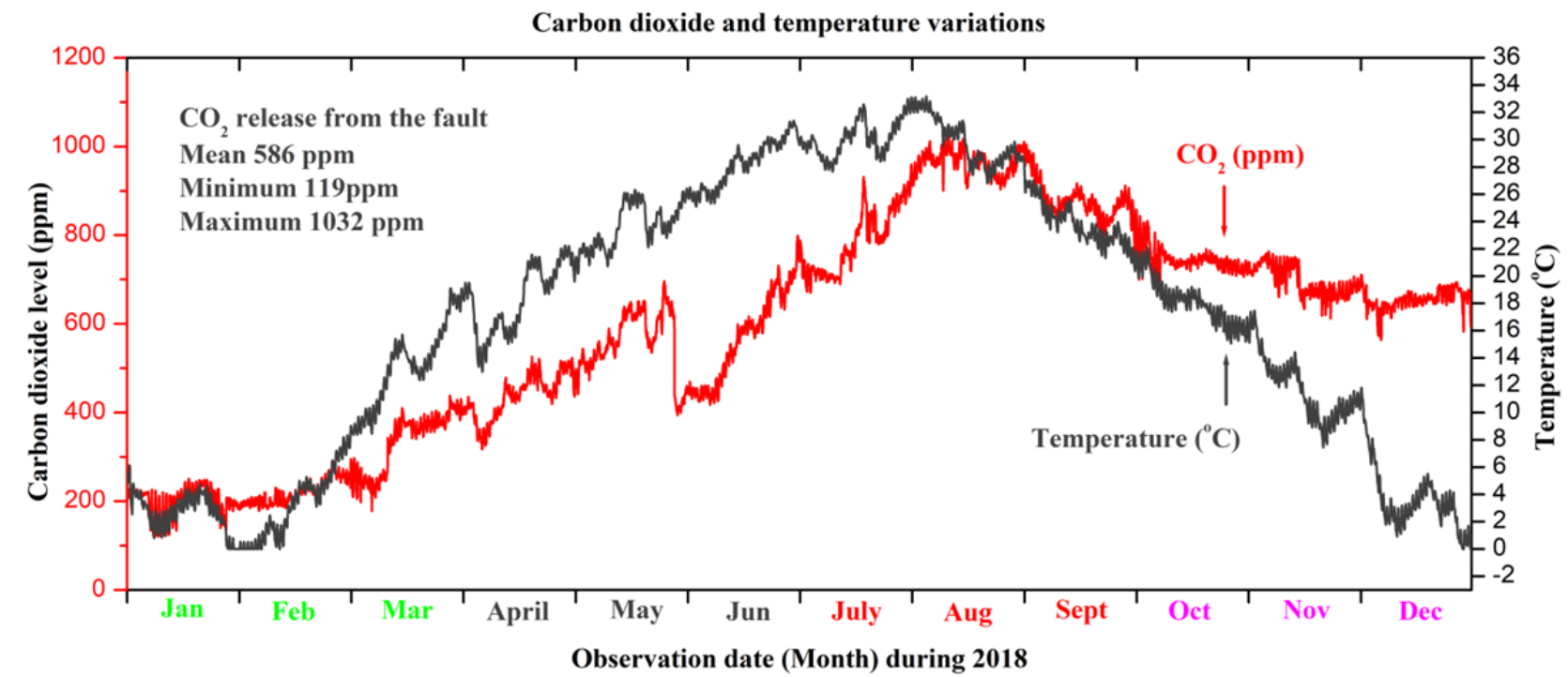

Fig. 2. Carbon dioxide level (ppm) observed from 1 January to 31 December during 2018, together with atmospheric temperature recorded. There is a short-term fluctuation of both carbon dioxide levels and atmospheric temperature on a long-term trend. The correlative coefficient between the carbon dioxide level and the temperature variation ranges from the mean value of 0.15 for frequency above $0.1 \mathrm{~Hz}$, up to 0.2 through 0.84 for frequency below $0.1 \mathrm{~Hz}$, generally exhibiting a normal correlation. Note that the data acquisition period is one minute for both carbon dioxide level and atmospheric temperature. Here, the data are re-sampled to obtain one mean value every 60 minutes. 
dioxide level ranges from 119 up to $1032 \mathrm{ppm}$, attributed to the seismically active fault. The annual mean level represents $586 \mathrm{ppm}$, compared to the global current level of $410 \mathrm{ppm}$, and remains higher than $280 \mathrm{ppm}$ as of the middle of $18^{\text {th }}$ century (Eggleton, 2013). The carbon dioxide flux seasonally oscillates on a long-term increasing background prior to the middle of August. At the beginning of September, the carbon dioxide level experiences short-term fluctuations on a long-term decreasing tend. Simultaneously recorded atmospheric temperature variations exhibit a positive correlation to carbon dioxide levels, demonstrating seasonal fluctuations on a long-term increasing or decreasing background (Chatterjee et al., 2018). The atmospheric temperature variation synchronizes with the carbon dioxide flux released from the borehole. The phenomenon would imply that more biologic activities result in higher carbon dioxide flux (Sorey et al., 1998; Jabro et al., 2008; Chatterjee et al., 2018). However, without knowing the isotopic composition of carbon in the carbon dioxide, it is impossible to evaluate the biology-chemistry process (Sorey et al., 1998). The link between atmospheric temperature variations and carbon dioxide emissions from the fault remains poorly estimated. But this is currently beyond the scope of this paper.

\section{Characteristics of Borehole-strain Signals}

Strain-depth profiles are recorded by using the distributed optic-fiber strain sensor. As illustrated in
Figs. 3-4, the strain signals from all observed-sites exhibit characteristics of good-quality borehole strain data with high reproducibility and continuity. Responses to solidearth tidal signals can't be detected due to the restriction of the strain acquisition accuracy of the Brillouin optical time-domain analysis (BOTDA). The strain signal clearly shows compaction due to elastic deformation and dilation due to plastic deformation (Zoback, 1992). The strain in fracture well-developed and shear zones mainly exhibit dilation. Between 2.0 and 7.5 meters, and from 12.0 downward to 74.5 meters of the borehole depth, there exist fracture well-developed calcite bedrocks. From 7.5 to 12.0 meters, and from 74.5 to the bottom (83.1 meters) of the borehole, two earthquake-induced ruptures (e.g., shear zone) are imbedded. The deformation of fracture-well developed bedrocks is generally stronger than that of ruptures filled with cement and brecciola. Compaction and dilation of fracture-well developed bedrocks are vulnerable to stress changes (Min et al., 2004). Compared to elastic compaction, plastic dilation governs the deformation of both fracture well-developed and shear zones. During the measurement period from 30 May to 2 June, the strain signals show gradually increasing dilation strain rates. The reverse fault of dip 70 degree mainly experiences dilation, with local compaction observed. The strain-depth profiles illustrate the heterogeneous deformation characteristics with compaction and dilation alternatively appearing, as evidenced by experiments (Violay et al., 2015). We show

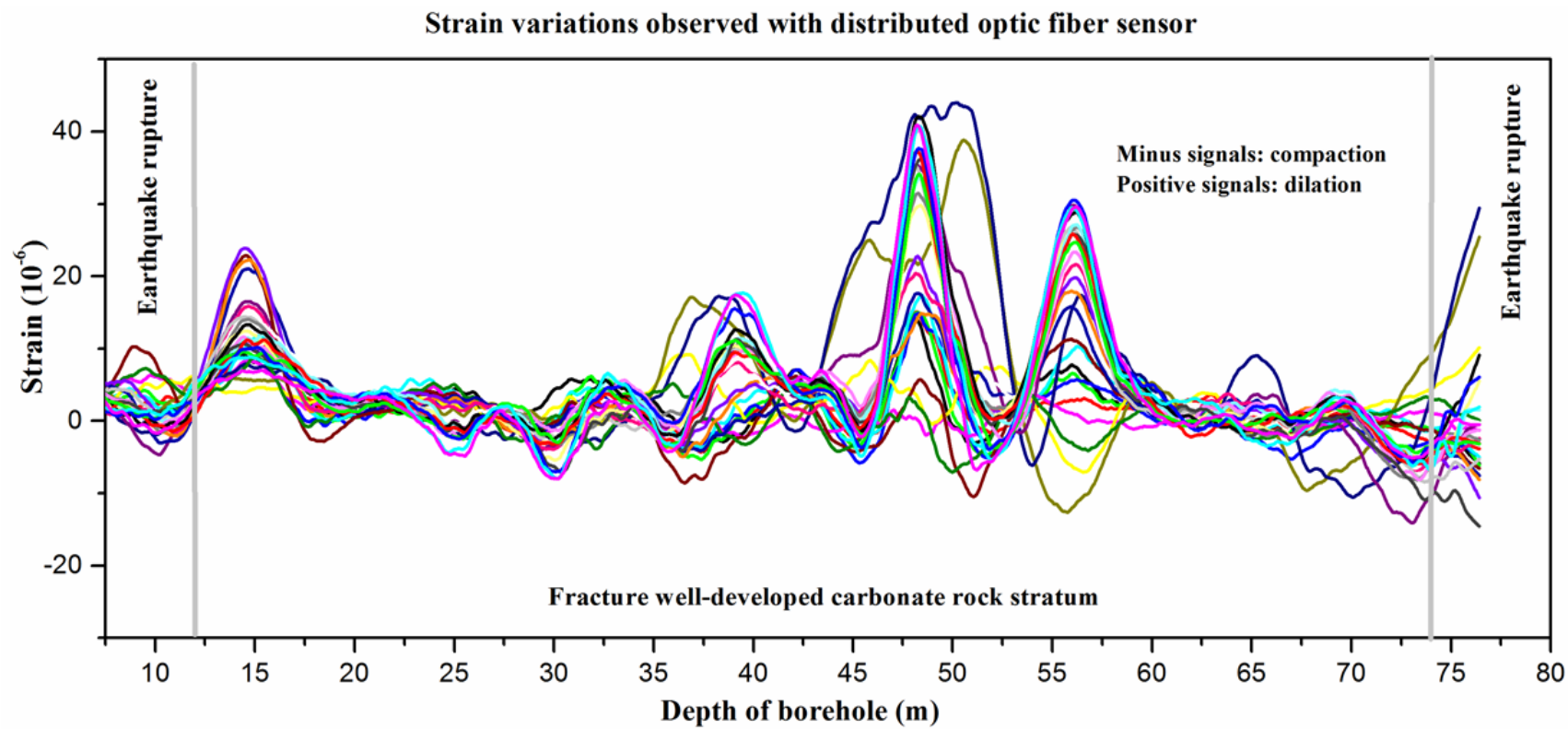

Fig. 3. Borehole strain $\left(1 \mu \varepsilon=10^{-6}\right)$ measured every 60 minutes with a distributed optic-fiber strain sensor from 29 May to 2 June in 2018. Gray lines represent the stratum interfaces. Two drilled shear-zones (e.g., earthquake-induced rupture) are located at the depth between 7.5 meter to 12 meter, and below the depth of 74.5 meter, respectively. Strain between the depth of 7.5 to 76.4 meter shows locally compaction and dilation, indicating local blockage or reopen of fluid paths. The fracture well-developed calcite bedrock mainly experiences dilation caused by plastic deformation, and in which the deformation is larger than that of the shear zones. The borehole is drilled crossing the upper and lower fault planes, and the borehole strain generally shows dilation-dominant deformation triggered by the reverse fault of dip 70 degree. On a dilation-governed deformation background, carbon dioxide level exhibits the increasing trend due to increments of permeability or mass diffusivity within the fluid paths. 
from Fig. 4 that the carbon dioxide increasing trend generally corresponds to the dilation of the seismically active fault over the same time-scale of the observation.

\section{Effects of Fault Deformation on Carbon Dioxide Variation}

As shown in Figs. 4(A) and 4(B), from 29 May to 2 June, the strain mainly exhibits dilation, and the carbon dioxide level shows a gradually increasing trend. Mechanically, the carbon dioxide level has changed due to variations of the waves on carbon dioxide emissions from the fault. permeability and the average velocity field associated with the mass transfer (Bravo, 2007). Dilation increases the dynamic permeability of fluid paths in the fault (Tamburello et al., 2018; Yin, 2018). Carbon dioxide fluctuations are happening as a result of partial blockage or reopen of the
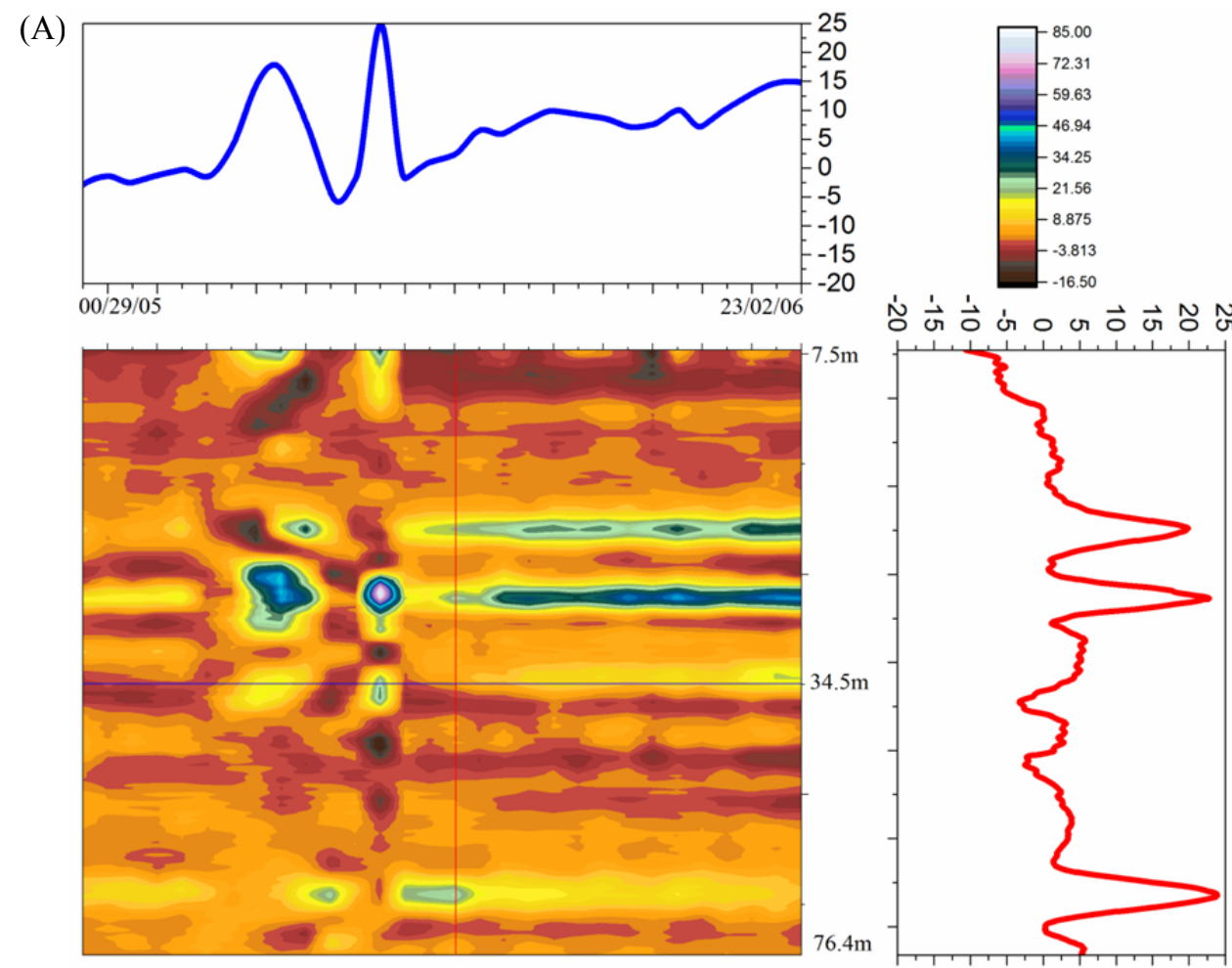

(B)

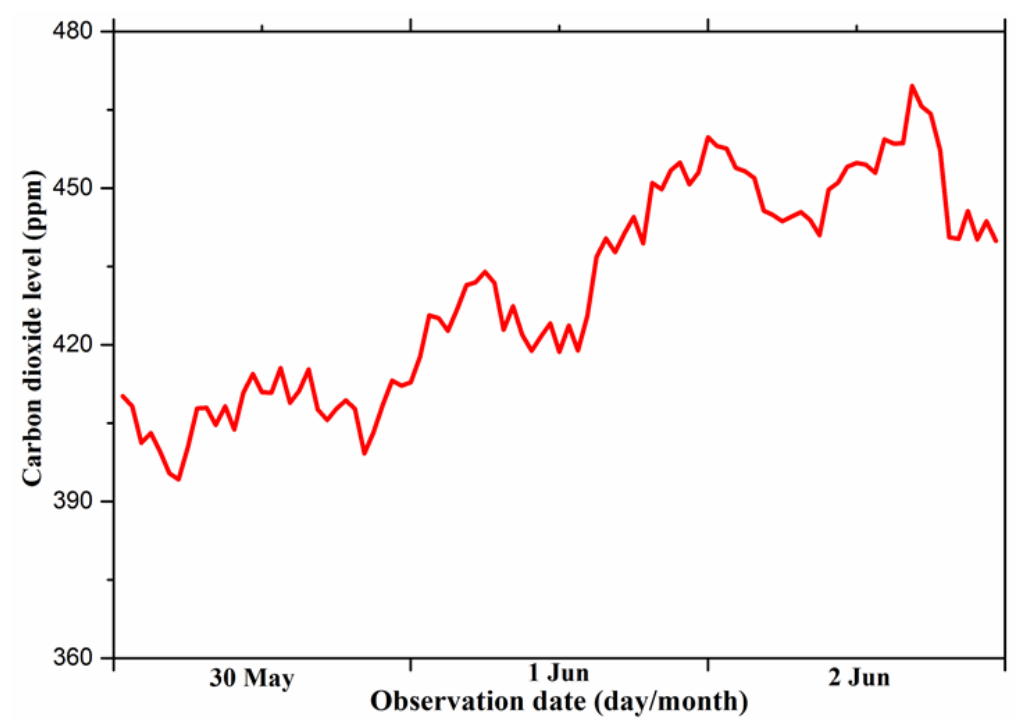

Fig. 4. (A) Space-time tomography of strains $\left(1 \mu \varepsilon=10^{-6}\right)$ varying with borehole depths and observation date from 29 May to 2 June in 2018. Upper inset: showing a time-strain profile at depth of 34.5 meters. Right inset: showing strain-depth profile at time of 12:00, May 31. Observed strain-depth profiles illustrate the heterogeneous deformation characteristics with compaction and dilation alternatively appearing, with the dilation dominating. (B) Carbon dioxide level (ppm) observed from 30 May to 2 June. It shows the increasing trend of carbon dioxide levels is generally influenced by the dilation of the seismically active fault. Note that the time scale of carbon dioxide observation correlates with the strain time scale. 
flow paths (Caine et al., 1996). Compaction and dilation of fluid paths (Violay et al., 2015; Yin, 2018), respectively, accelerate and decelerate carbon dioxide emissions from the fault. The links between the variations of carbon dioxide levels and the strain changes raise several interesting questions such as what happens to carbon dioxide after strain change, and how the fault deformation mechanically control the carbon dioxide emission. The mechanism may be contributed to either the fault valve-driven fluid flow (Frank et al., 2015) or the water-hammer effect (Yin, 2018). Here, we preliminarily propose a mass-wave propagation model (e.g., interaction of shock waves with advectiondiffusion of mass, namely the gas hammer effect) to physically explain a rise or drop of carbon dioxide levels due to dilation or compaction of fluid paths. Initial onset of compaction causes permeability reduction, leading to partial or complete blockage of the fluid path (Min et al., 2004; Yin, 2018). The extreme compaction of the fluid path can trigger an elevated pressure at a blockage site (Millar et al., 2004), which can be estimated by the Joukowsky equation (Ghidaoui et al., 2005). Carbon dioxide is significantly trapped in the well-sealed blockage site, and its level continuously increases. After initial compaction followed by dilation, partial or complete fluid-path blockage suddenly reopen, causing a sudden permeability rise and leading to a flow jet (Levy et al., 1996; Min et al., 2004) and shock waves (Liepman et al., 1957; Talwani and Acree, 1985) propagating through the fluid path. Mass waves (Yang, 2018), obeyed by the advection-diffusion law, of carbon dioxide are simultaneously produced and accelerated due to the shock wave. In the following section, we discuss the mechanical effect of shock

\section{Effects of Shock on Mass Transfer}

A macroscopic one-dimensional analytical model for describing pressure waves in saturated porous media is governed by (Talwani and Acree, 1985; Yang et al., 2015; Yang et al., 2018; Yin, 2018):

$$
P(X, t)=P^{L}\left[1-\operatorname{erf}\left(\frac{X}{\sqrt{4 D_{p} t}}\right)\right]
$$

where $P^{L}=\Delta P_{\max }$ is the initial pressure at the blockage site (distance $\mathrm{X}=0$ ) at the onset of the compaction deformation (time $\mathrm{t}=0), \Delta P_{\max }$ is the pressure change at the blockage site during compaction (Ghidaoui et al., 2015; Yin, 2018), and $P(X, t)$ is the pore-fluid pressure jump in the front of the wave. $D_{p}=K_{d} K_{e} / \varphi \eta_{f}$ is the pressure diffusivity, $\gamma$ is the specific heat capacity ratio, and $\eta_{f}$ is the viscosity. By using some mathematical simplifications (Levy et al., 1996), it yields:

$$
\varepsilon(X, t)=\alpha\left[P(X, t)-P_{o}\right]
$$

$U(X, t)=\frac{K_{d}}{\eta_{f}} P^{L} \frac{1}{\sqrt{\pi D_{p} t}} e^{-\frac{X^{2}}{4 D_{p} t}}$ here $\varepsilon(X, t)$ is the strain jump, and $U(X, t)$ is the fluid velocity jump. $\alpha=\left(\phi+(\gamma-1)(1-\phi) \tau_{s}\right) /\left(\lambda_{s}(\gamma-1)\right)$ represents the dependence of the strain on the pressure drop. $\lambda_{s}$ denotes the Lame constant of the elastic solid. $\tau_{s}$ is the tortuosity of porous media. $X$ is the shockwave travelling distance (Hoover et al., 2014). A one-dimensional (1D) advection-diffusion of fluids in porous media is given by (Bravo, 2007):

$$
\frac{\partial C(X, t)}{\partial t}+\frac{\partial}{\partial X}\left(C(X, t) U(X, t)-D^{e} \frac{\partial C(X, t)}{\partial X}\right)=0
$$

where $\varphi$ is the porosity, $D^{e}=\frac{\varphi}{\tau_{s}} D_{m}$ is the effective diffusivity of mass (Yang, 2018) in the porous media, $C(X, t)$ stands for the concentration, and $D_{m}$ is the molecular diffusivity. The first contribution, $C(X, t) U(X, t)$, describes advection driven by velocity shockwaves, and the second, $D^{e} \frac{\partial \mathcal{C}(X, t)}{\partial X}$, describes diffusion driven by concentration gradients. By using some mathematical simplifications (Sun, 1995), an analytical solution of Eq. (4) with the boundary conditions, $C(X, 0)=C_{0}$ at the blockage site $(\mathrm{X}=0)$ at the onset of the compaction deformation (time $\mathrm{t}=0$ ), reads

$$
C(X, t)=\frac{C_{0}}{2} \operatorname{erfc}\left(\frac{X-U(X, t) t}{2 \sqrt{D^{e} t}}\right)
$$

Eq. (5) describes the physics of the propagation of mass shockwaves. Note that the penetration of the shockwave (e.g., $U(X)$ ) into the fluid path mechanically controls carbon dioxide transfer.

As shown in Fig. 5, carbon dioxide is transferred as mass-waves inside a fluid path due to processes of diffusion and convection. Diffusion is strongly influenced by the effective diffusivity, while advection is governed by the shockwave of the fluid velocity. The two factors cause a propagating mass wave with an elevated carbon dioxide level in the front of the wave through the fluid path. A key feature of the model is that the permeability increment by dilation is capable of initiating a propagating mass wave due to the pressure jump. Here, it is assumed that permeability changes indicate dilation or compaction of fluid paths (Yin, 2018). The fracture sealing and syn-kinematic fracturing (Yin, 2018) leads to a decrease or rise of the permeability. As the permeability increases, the fluid velocity shockwave is enhanced, causing the advection acceleration. However, compaction locally blocks the flow path (Min et al., 2004), causing permeability reduction, and the carbon dioxide level decreases. In contrast, dilation partially or completely reopens the conduit blockage, leading to permeability increment and causing a rise of carbon dioxide levels throughout the plastic deformation. Fracture deformations control the permeability evolution of the fluid-path (Caine et al., 1996; Yin, 2018), which is correlative with the pressure diffusivity and shockwaves of the fluid velocity. Our results show that the 

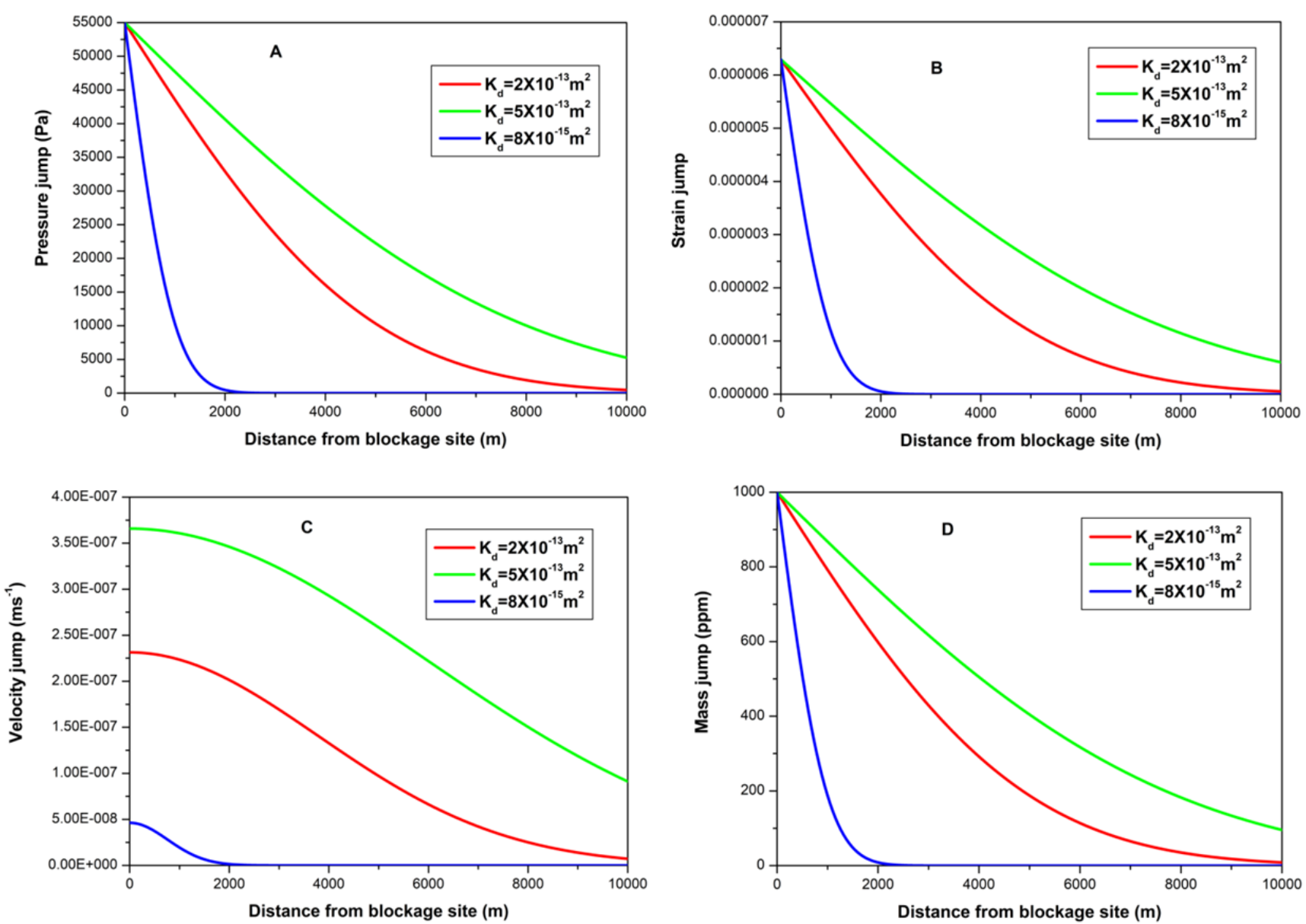

Fig. 5. Model results. Propagation of (A) pressure shockwave, (B) strain shockwave, (C) fluid velocity shockwave, and (D) mass wave with distance as function of variable dynamic permeability. Here, we assume (e.g., Yin, 2018) $\varphi=0.1, K_{e}=$ $10 \mathrm{GPa}, \eta_{f}=10^{-5} \mathrm{~Pa} \cdot \mathrm{s}, P^{L}=\Delta P_{\max }=55 \mathrm{kPa}, \tau_{\mathrm{s}}=1.0$ and $C_{0}=2000 \mathrm{ppm}$ at the time scale of $t=3600 \mathrm{~s}$.

shear dilation causes the concentration of fluid flow along connected shear fractures (Min et al., 2004). It is the first time that a physical model describing the mass shockwave propagation in porous media has been developed, physically explaining the change of carbon dioxide levels due to dilation or compaction of fluid paths in natural faults. The penetration of the shockwaves into the fluid path mechanically controls carbon dioxide migration. Here, a case study is completed to preliminarily explain the link between the fault deformation and the carbon dioxide variation as observed in Fig. 5. Without sources of carbon dioxide known in the fault, the true realization of carbon dioxide flux observed during the fault deformation is impossible by the numerical analysis. Nevertheless, this demonstration represents an important step toward interactions of mass transfer and shockwaves in seismically active faults, and opens the door to applications such as underground carbon dioxide monitoring and BOTDA-based strain measurements in boreholes.

\section{CONCLUSIONS}

The in situ monitoring has been carried out for the carbon dioxide level attributed to a seismically active fault, by using the underground borehole of depth 120.0 meters, with atmospheric temperature simultaneously recorded. Use has been made of the infrared technology-based instrument to detect progressive carbon dioxide levels. The distributed optic-fiber strain sensor is mounted into the borehole of depth 83.1 meters, and continuously records strain signals at the spatial interval of 0.5 meters along the longitudinal direction of the borehole. Of particular interest is the seasonal fluctuation of carbon dioxide levels on a long-term increasing or decreasing background. The carbon dioxide increasing trend is influenced by the dilation deformation of the seismically active fault over the same time scale of the observations. We preliminarily propose a mass-wave propagation model (e.g., interaction of the shock waves with the advection-diffusion of mass, namely the gas hammer effect) to physically explain a rise or drop of carbon dioxide levels due to dilation or compaction of fluid paths in natural faults. A physical connection is made between the fault deformation and the change in carbon dioxide flux. The penetration of the shockwave into the fluid path mechanically controls carbon dioxide migration. The mass-wave propagation induced by the fault deformation mainly characterizes carbon dioxide emissions from the seismically active fault. 
Although we can't identify how much carbon dioxide is produced by the fracture well-developed calcite bedrocks and earthquake ruptures, and how much contribution of deep-seated carbon sources is to such recorded carbon dioxide level. Studying the origin of carbon dioxide is beyond the scope of this paper. Because of spatially heterogeneous deformation of natural faults, somewhere local dilation governs deformation, while compaction dominates in other segments of the fault. The variation of carbon dioxide levels macroscopically represents the response to the general deformation tendency of the nature fault. Due to stress changes in faults, the fault deformation alters strains followed by changes of permeability in the fluid path (Violay et al., 2015). Then upward migration of carbon dioxide is influenced, and variations of the carbon dioxide level accordingly change. At least, it is suggested that the fault deformation mechanically drive carbon dioxide emissions released from the seismically active fault. Biological processes and links between the fault deformation and the amounts of carbon dioxide emissions should be deeply evaluated in the future work.

\section{ACKNOWLEDGMENTS}

The support of the National Natural Science Foundation of China under Grant No. 41874113 is acknowledged. This work was partially supported by research grant of Institute of Crustal Dynamics, China Earthquake Administration (ZDJ2016-20). The anonymous reviewers have given comments and suggestions, which have much improved this manuscript.

\section{DISCLAIMER}

The authors declare no competing interests.

\section{REFERENCES}

Ali, M.A., Assiri, M. and Dambul R. (2017). Seasonal Aerosol Optical Depth (AOD) variability using satellite data and its comparison over Saudi Arabia for the period 2002-2013. Aerosol Air Qual. Res. 17: 1267-1290.

Ballantyne, A.P., Alden, C.B., Miller, J.B., Tans, P.P. and White, J.W.C. (2012). Increase in observed net carbon dioxide uptake by land and oceans during the past 50 years. Nature 488:70-72.

Bansal, O., Singh, A. and Singh, D. (2019). Aerosol characteristics over the northwestern Indo-Gangetic Plain: Clear-sky radiative forcing of composite and black carbon aerosol. Aerosol Air Qual. Res. 19: 5-14.

Bari, D. and Bergot, T. (2018). Influence of environmental conditions on forecasting of an advection-radiation fog: A case study from the Casablanca region, Morocco. Aerosol Air Qual. Res. 18: 62-78.

Bravo, M.C. (2007). Effect of transition from slip to free molecular flow on gas transport in porous media. $J$. Appl. Phys. 102: 074905.

Caine, J.S., Evans, J.P. and Forster, C.B. (1996). Fault zone architecture and permeability structure. Geology
24: $1025-1028$.

Chatterjee, A., Roy, A., Chakraborty, S., Karipot, A.K., Sarkar, C., Singh, S., Ghosh, S.K., Mitra, A. and Raha, R. (2018). Biosphere atmosphere exchange of $\mathrm{CO}_{2}, \mathrm{H}_{2} \mathrm{O}$ vapour and energy during spring over a high altitude Himalayan forest in eastern India. Aerosol Air Qual. Res. 18: 2704-2719.

Chatterjee, A., Devara, P.C.S., Balasubramanian, R. and Jaffe, D.A. (2019). Aerosol Climate Change Connection (AC3) special issue: An overview. Aerosol Air Qual. Res. 19: 1-4.

Dlugokencky, E. (2016). Annual mean carbon dioxide data. Earth System Research Laboratory, NOAA.

Eggleton, T. (2013). A short introduction to climate change, Cambridge University Press, ISBN 9781107618763.

Frank, W.B., Shapiro, N.M., Husker, A.L., Kostoglodov, V., Bhat, H.S. and Campillo, M. (2015). Along-fault pore-pressure evolution during a slow-slip event in Guerrero, Mexico, Earth Planet. Sci. Lett. 413: 135143.

Gao, S., Silver, P.G., Linde, A.T. and Sacks, I.S. (2000). Annual modulation of triggered seismicity following the 1992 Landers earthquake in California. Nature 406: 500-504.

Ghidaoui, M.S., Zhao, M., McInnis, D.A. and Axworthy, D.H. (2005). A review of water hammer theory and practice. Appl. Mech. Rev. 58: 49-75.

Hoover, W.G., Hoover, C.G. and Travis, K.P. (2014). Shock-wave compression and Joule-Thomson expansion. Phys. Rev. Lett. 112: 144504.

Huang, C.H. and Tan, C.S. (2014). A review: $\mathrm{CO}_{2}$ utilization. Aerosol Air Qual. Res. 14: 80-499.

Hunt, J.A., Zafu, A., Mather, T.A., Pyle, D.M. and Barry, P.H. (2017). Spatially variable $\mathrm{CO}_{2}$ degassing in the main Ethiopian rift: Implications for magma storage, volatile transport, and rift-related emissions. Geochem. Geophys. Geosyst. 18: 3714-3737.

Irwin, W.P. and Barnes, I. (1980). Tectonic relations of carbon dioxide discharges and earthquakes. J. Geophys. Res. 85: 3115-3121.

Ishikawa, N. and Sekiguchi, K. (2018). Measurements of the size and composition of volatile particles generated from a heated tobacco product with aerosol fixation agents. Aerosol Air Qual. Res. 18: 2538-2549.

Jabro, J.D., Sainju, U., Stevens, W.B. and Evans R.G. (2008). Carbon dioxide flux as affected by tillage and irrigation in soil converted from perennial forages to annual crops. J. Environ. Manage. 88: 1478-1484.

Jean, J.S., Hsiang, H.S., Li, Z.H., Wong, C.L., Yang, H.J., Yang, K.M., Wang, C.L., Lin, H.W. and Kuo, C.C. (2015). Influence of supercritical $\mathrm{CO}_{2}$ on the mobility and desorption of trace elements from $\mathrm{CO}_{2}$ storage rock sandstone and caprock shale in a potential $\mathrm{CO}_{2}$ sequestration site in Taiwan. Aerosol Air Qual. Res. 16: 1730-1741.

Jen, C.P., Li, C. and Zhang, K.N. (2017). Effects of Injection pressure on geological $\mathrm{CO}_{2}$ storage in the northwest Taiwan Basin. Aerosol Air Qual. Res. 17: 1033-1042. 
Keeling, C.D., Piper, S.C., Whorf, T.P. and Keeling, R.F. (2011). Evolution of natural and anthropogenic fluxes of atmospheric $\mathrm{CO}_{2}$ from 1957 to 2003. Tellus B 63: 1-22.

Levy, A., Sorek, S., Ben-Dor, G. and Skews, B. (1996). Waves propagation in saturated rigid porous media: Analytical model and comparison with experimental results. Fluid Dyn. Res. 17: 49-65.

Li, J.Y. and Biswas, P. (2017). Optical characterization studies of a low-cost particle sensor. Aerosol Air Qual. Res. 17: 1691-1704.

Liepman, H.W. and Roshko, A. (1957). Elements of gas dynamics, John Willey \& Sons.

Lin, N.H., Chang, M.B., Hwang, J., Kaneyasu, N. and Zhang, R.Z. (2018). Overview of the special issue "aerosol source, transport, chemistry, and emission control" for the $10^{\text {th }}$ Asian aerosol conference 2017. Aerosol Air Qual. Res. 18: 1515-1518.

Liu, C.C., Linde, A.T. and Sacks, I.S. (2009). Slow earthquakes triggered by typhoons. Nature 459: 833836.

Mazot, A., Rouwet, D., Taran, Y., Inguaggiato, S. and Varley, N. (2011). $\mathrm{CO}_{2}$ and He degassing at El Chichon volcano, Chiapas, Mexico: Gas flux, origin and relationship with local and regional tectonics. Bull. Volcanol. 73: 423-441.

Miller, S.A., Collettini, C., Chiaraluce, L., Cocco, M., Barchi, M. and Kaus, B.J.P. (2004). Aftershocks driven by a high-pressure $\mathrm{CO}_{2}$ source at depth. Nature 427: 724-727.

Min, K.B., Rutqvist, J., Tsang, C.F. and Jing, L.R. (2004). Stress-dependent permeability of fractured rock masses: A numerical study. Int. J. Rock Mech. Min. Sci. 41: 1191-1210.

Mohr, S.H., Wang, J., Ellem, G., Ward, J. and Giurco, D. (2015). Projection of world fossil fuels by country. Fuel 141: 120-135.

Phelps, J., Blackford, J., Holt, J. and Polton, J. (2015). Modelling large-scale $\mathrm{CO}_{2}$ leakages in the North Sea. Int. J. Greenhouse Gas Control 38: 210-220.

Smil, V. (2003). The Earth's biosphere: Evolution, dynamics and change. MIT Press. ISBN 978-0-262-69298-4.

Soong, Y., Howard, B.H., Hedges, S.W., Haljasmaa, I., Warzinski, R.P., Irdi, G. and McLendon, M.R. (2014). $\mathrm{CO}_{2}$ sequestration in saline formation. Aerosol Air Qual. Res. 14: 522-532.

Sorey, M.L., Evans, W.C., Kennedy, B.M., Farrar, C.D., Hainsworth, L.J. and Hausback, B. (1998). Carbon dioxide and helium emissions from a reservoir of magmatic gas beneath Mammoth Mountain, California. J. Geophys. Res. 103: 15303-15323.

Sun, N.Z. (1995). Mathematical modelling of groundwater pollution. Springer-Verlag, New York.

Talwani, P. and Acree, S. (1985). Pore pressure diffusion and the mechanism of reservoir-induced seismicity. Pure Appl. Geophys. 122: 947-965.
Tamburello, G., Pondrelli, S., Chiodini, G. and Rouwet, D. (2018). Global-scale control of extensional tectonics on $\mathrm{CO}_{2}$ earth degassing. Nat. Commun. 9: 4608.

Vilhena, M.T.D. (1992). An analytical solution of the steady state convective diffusion equation with space dependent diffusion Coefficient. J. Membr. Sci. 71: 5156.

Violay, M., Gibert, B., Mainprice, D. and Burg, J.P. (2015). Brittle versus ductile deformation as the main control of the deep fluid circulation in oceanic crust. Geophys. Res. Lett. 42: 2767-2773.

Wang, S., Yang, D.X. and Zeng, R.S. (2018). Immiscible multiphase flow behaviours of water-oil- $\mathrm{CO}_{2}$ ternary system flooding using X-ray CT. Aerosol Air Qual. Res. 18: 1089-1101.

Werner, C., Schmidt, H.P., Gerten, D., Lucht, W. and Kammann, C. (2018). Biogeochemical potential of biomass pyrolysis systems for limiting global warming to $1.5^{\circ} \mathrm{C}$. Environ. Res. Lett. 13: 044036.

Wright, L.P., Zhang, L.M., Cheng, I., Aherne, J. and Wentworth, G.R. (2018). Impacts and effects indicators of atmospheric deposition of major pollutants to various ecosystems - A review. Aerosol Air Qual. Res. 18: 1953-1992.

Yang, D.X., Zhang, Y. and Wang, S. (2014). Analysis of $\mathrm{CO}_{2}$ migration during nanofluid based supercritical $\mathrm{CO}_{2}$ geological storage in saline aquifers. Aerosol Air Qual. Res. 14: 1411-1417.

Yang, D.X., Li, Q. and Zhang, L.Z. (2015). Propagation of pore pressure diffusion waves in saturated porous media. J. Appl. Phys. 117: 134902.

Yang, D.X. (2018). Green functions of mass diffusion waves in porous media. J. Phys. Commun. 2: 031003.

Yang, D.X., Doschoris, M., and Zhang, L.Z. (2018). Analysis of pressure diffusion-wave fields in matrixfracture media using Green functions of frequency domain. J. Appl. Phys. 124: 074902.

Yang, W.M., Zhu, R., Zhang, C. and Li, Z. (2017). Application and performance test of a small aerosol sensor for the measurement of aerosolized DNA strands. Aerosol Air Qual. Res. 17: 2358-2366.

Yin, A. (2018). Water hammers tremors during plate convergence. Geology 46: 1031-1034.

Yu, C.H., Huang, C.H. and Tan, C.S. (2012). A review of $\mathrm{CO}_{2}$ capture by absorption and adsorption. Aerosol Air Qual. Res. 12: 745-769.

Zoback, M.L. (1992). First and second order patterns of tectonic stress in the Lithosphere: The World Stress Map Project. J. Geophys. Res. 97: 11703-11728.

Received for review, June 2, 2019 Revised, July 10, 2019 Accepted, July 18, 2019 